\title{
LOS HORNOS ALTOS DEL CERRO DE LOS MÁRTIRES (SAN FERNANDO, CÁDIZ). NUEVAS APORTACIONES DEL PROYECTO ARQUEOLÓGICO CAMPOSOTO - TORREGORDA
}

\author{
THE HIGH KILNS OF CERRO DE LOS MÁRTIRES (SAN FERNANDO, CÁDIZ). \\ NEW INFORMATIONS ABOUT THE ARCHAEOLOGICAL PROJECT CAMPOSOTO - TORREGORDA
}

\author{
José J. DÍAZ RODRÍGUEZ ${ }^{1 *}$ y Alicia ARÉVALO ${ }^{1 * *}$
}

\author{
${ }^{1}$ Dpto. de Historia, Geografía y Filosofía, Universidad de Cádiz, Avda. Dr. Gómez Ulla 1, 11001, Cádiz \\ * Correo electrónico: josejuan.diaz@uca.es \\ ** Correo electrónico: alicia.arevalo@uca.es
}

Resumen: Presentamos en este trabajo los resultados de la intervención realizada en el año 2017 en el seno del proyecto Camposoto - Torregorda sobre los restos de un horno cerámico documentado en la parte alta del Cerro de los Mártires, el cual fue amortizado y usado como vertedero entre mediados del s. II y el s. III d.C.

Palabras Clave: Alfarería, horno, época romana, vertedero, Cerro de los Mártires.

\begin{abstract}
In this paper, we show the result of a dig carried out in 2017 within the Camposoto - Torregorda Project. The remains of a ceramic kiln were discovered in the slope of Cerro de los Mártires. This structure was amortized and used as a pottery dump between the middle of the s. II and s. III A.D.
\end{abstract}

Keywords: Pottery, ceramic kiln, Roman Times, dump, Cerro de los Mártires.

Sumario: 1. Introducción. 2. El yacimiento de Gallineras - Cerro de los Mártires (San Fernando, Cádiz). 3. Los trabajos arqueológicos acometidos en el 2017 en el horno H-1. 4. Conclusiones y perspectivas de futuro. 5. Agradecimientos. 6. Bibliografía.

\begin{abstract}
A Antonio Sáez Espligares, quién desde su amor por la Arqueología, ha sabido transmitirnos el valor del Patrimonio que atesora San Fernando.
\end{abstract}

\section{Introducción}

En este estudio presentamos algunos de los resultados obtenidos dentro de los trabajos realizados en el ámbito del Proyecto Arqueológico de la zona Camposoto - Torregorda en los términos municipales de Cádiz y San Fernando, dirigido por Dña. Alicia Arévalo González y D. José Ramos Muñoz. El proyecto cuenta con la autorización del acceso a terrenos militares por parte del Ministerio de Defensa y con el visado y autorización para la realización de actividades arqueológicas por parte de la Dirección General de Bellas Artes y de Archivos y Bibliotecas perteneciente al Ministerio de Educación, Cultura y Deporte.

Este proyecto se sitúa en una de las líneas prioritarias de la Universidad de Cádiz, en el cuadro de las actividades del Campus de Excelencia Internacional del Mar (Ceimar), que incluye entre sus grandes áreas de estudio el "Valor Cultural del Mar". Pretende el estudio diacrónico de las ocupaciones humanas ocurridas en la zona litoral situada entre Torregorda y Camposoto (Figura 1). El objetivo principal es analizar los procesos históricos, económicos y sociales acontecidos en este medio natural desde las sociedades cazadoras-recolectoras de la Prehistoria hasta época Moderna y Contemporánea. Conviene resaltar que se trata de una zona que tiene la peculiaridad, al considerarse una zona de importancia geoestratégica militar, de no haber sido estudiada en proyectos anteriores de estudios arqueológicos que se han desarrollado en la zona de San Fernando.

Dentro de este proyecto se han acometido diferentes trabajos agrupados en tres bloques. El primero, ha sido la recopilación y análisis de la documentación cartográfica de la zona, contando en la actualidad con 311 documentos catalogados. Destaca la gran variedad de nacionalidades que están 

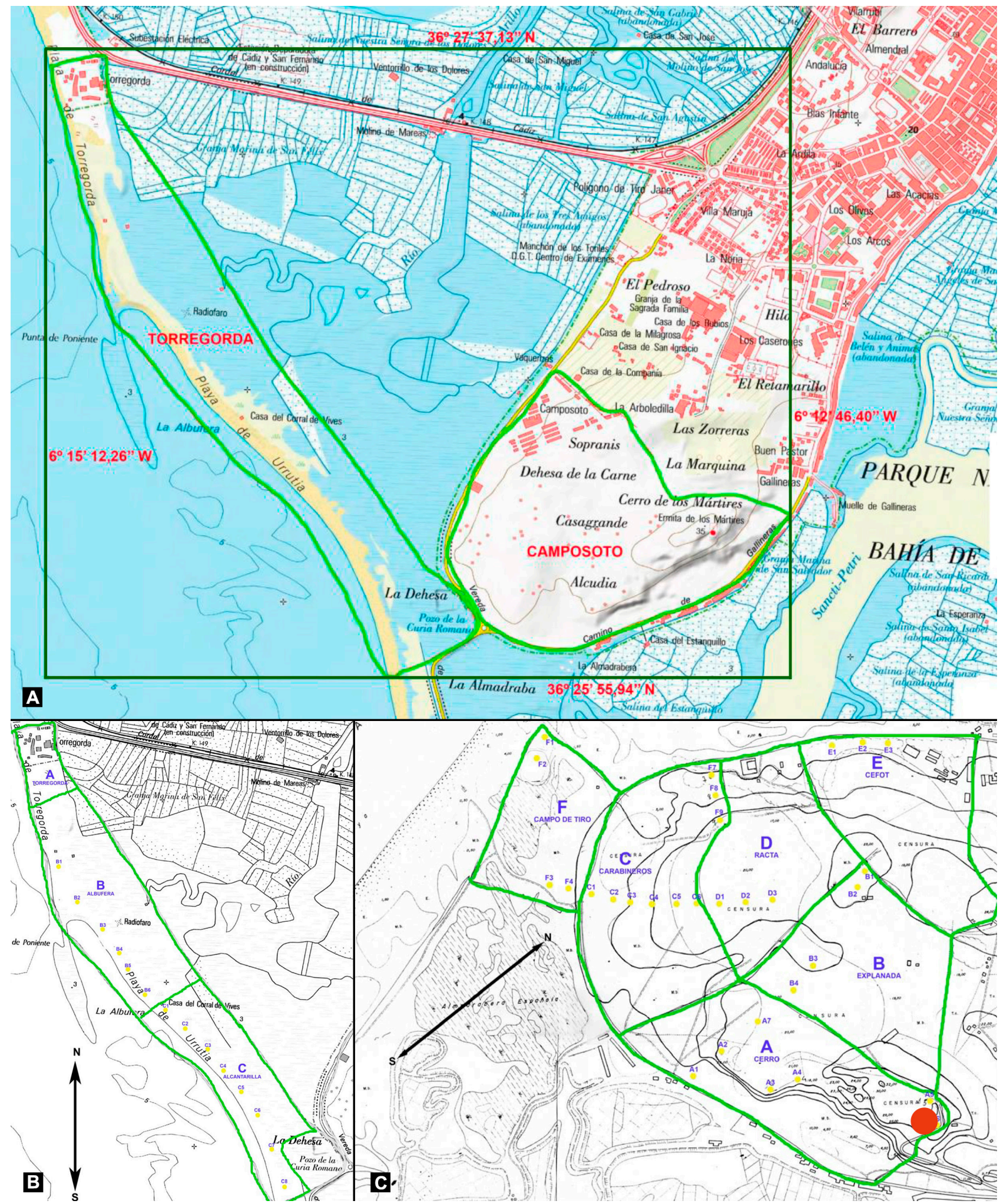

Figura 1. Planimetría de la costa de San Fernando con la señalización de las zonas de estudio del Proyecto Camposoto - Torregorda (a), con la subdivisión en sectores en Torregorda (b) y Camposoto (c). 
presentes, fruto de los diversos episodios históricos que tuvieron lugar en el ámbito de la bahía, ya que disponemos de cartografía de origen español, holandés, francés, inglés, italiano e incluso portugués; con una cronología que abarca desde el siglo XVI hasta el siglo XX, además de ser de múltiples temáticas, entre los que destacan los aspectos militares y marítimos, y procedentes de diversas instituciones. En este sentido, casi la mitad de la documentación procede del Archivo Histórico Provincial de Cádiz, seguida de la documentación extraída del Archivo General de Simancas y del Institut Cartogràfic i Geològic de Catalunya (Gómez, 2019 a y b).

El segundo bloque, ha consistido en la prospección arqueológica al suroeste de la bahía de Cádiz entre los términos municipales de Cádiz y San Fernando, en el interior de las instalaciones militares del Centro de Formación de Tropa no 2 (CEFOT), popularmente conocido como cuartel de Camposoto, y del Centro de Ensayos Torregorda (Figura 2a). Se trata de una zona de relieve bajo, cuya máxima altitud se sitúa en el Cerro de los Mártires, ubicado en el sector SE del referido recinto militar, con una altitud de 32 metros sobre el nivel del mar. Geológicamente el emplazamiento está rodeado en su mayor parte, a excepción del norte, por un dominio de llanura mareal (marisma) en el que domina un ambiente marino-salobre, pero que está situado sobre un afloramiento terciario en el que aparece un isleo de materiales triásicos, de facies Keuper, que aflora en relación a una falla normal con dirección $\mathrm{N} 40^{\circ} \mathrm{E}$. Las fases de trabajo realizadas han permitido un acercamiento a un territorio prácticamente desconocido por la comunidad científica al estar en propiedad del Ministerio de Defensa; como por ejemplo la localización de tramos del $\mathrm{Ca}$ mino del Arrecife con más de dos metros de alzado o los lienzos y solería del mismo desmontados por el efecto del llamado terremoto de Lisboa que asoló también la bahía de Cádiz en 1755 (Figura 2b y c), que fueron sacados a la luz bajo el cordón dunar tras el temporal Emma acaecido en febrero-marzo de 2018. Estos trabajos de prospección y visitas han venido a confirmar las hipótesis previas de interés y potencialidad del área para la reconstrucción de los procesos históricos en la bahía de Cádiz, cuyos primeros resultados fueron dados a conocer públicamente en los XX Encuentros de Historia y Arqueología de San Fernando, celebrados en el 2017 en la localidad de San Fernando.

Por último, se han llevado a cabo sendas actividades arqueológicas de campo dentro de las insta- laciones militares del Centro de Ensayos Torregorda y del acuartelamiento de Camposoto. En la primera zona, las actuaciones se han concentrado en el entorno de La Alcantarilla, cuyo objetivo principal era comprobar la hipótesis de ubicación del fuerte de La Alcantarilla; pues con anterioridad, se había llevado a cabo un amplio trabajo de estudio de la cartografía histórica de la zona y de las Actas Capitulares del Cabildo de la ciudad de Cádiz. Este trabajo realizado por José María Aceytuno en su Trabajo Fin de Máster titulado "La Alcantarilla de la Isla de León. Aproximación histórico-arqueológica”, sirvió de base para plantear una hipótesis de ubicación del Fuerte de La Alcantarilla. Los distintos sondeos realizados han permitido constatar la existencia de estructuras viarias y defensivas en la zona (Figura 2d). Especialmente han aportado interesantes datos relacionados con las estructuras arquitectónicas que componen el fuerte, más allá del arranque del foso y la relación entre la fortaleza y el paso de La Alcantarilla. Todo ello está siendo objeto de un estudio en profundidad en el seno de una Tesis Doctoral.

En cuanto a la segunda zona, cuyos resultados abordamos detenidamente en este trabajo, destaca el sondeo de comprobación de restos arqueológicos desarrollados en la extensión del yacimiento de Gallineras - Cerro de los Mártires en el interior del recinto militar de Camposoto, próximo a la ermita existente en ese espacio del término municipal de San Fernando. La actuación se ha desarrollado en la denominada como zona A1 del proyecto, que se corresponde con el área más elevada del Cerro de los Mártires, ubicando el sondeo en la ladera que mira hacia el caño de Sancti Petri, inmediato al cercado que separan los terrenos militares de los municipales.

\section{El yacimiento de Gallineras - Cerro de los Mártires (San Fernando, Cádiz)}

La villa romana de Gallineras - Cerro de los Mártires es quizás uno de los yacimientos de época romana más importantes emplazados en el T.M. de San Fernando. Se extiende por la ladera sur de la citada elevación, siendo el punto más alto de la llamada Antipolis, una de las islas de la Gades romana que menciona Estrabón. Se emplazó muy cerca del cauce del caño de Sancti Petri, utilizando las salinas, las marismas circundantes para el aprovechamiento de los recursos del mar, así como las tierras interiores para la explotación agrícola (Figura 3a). 

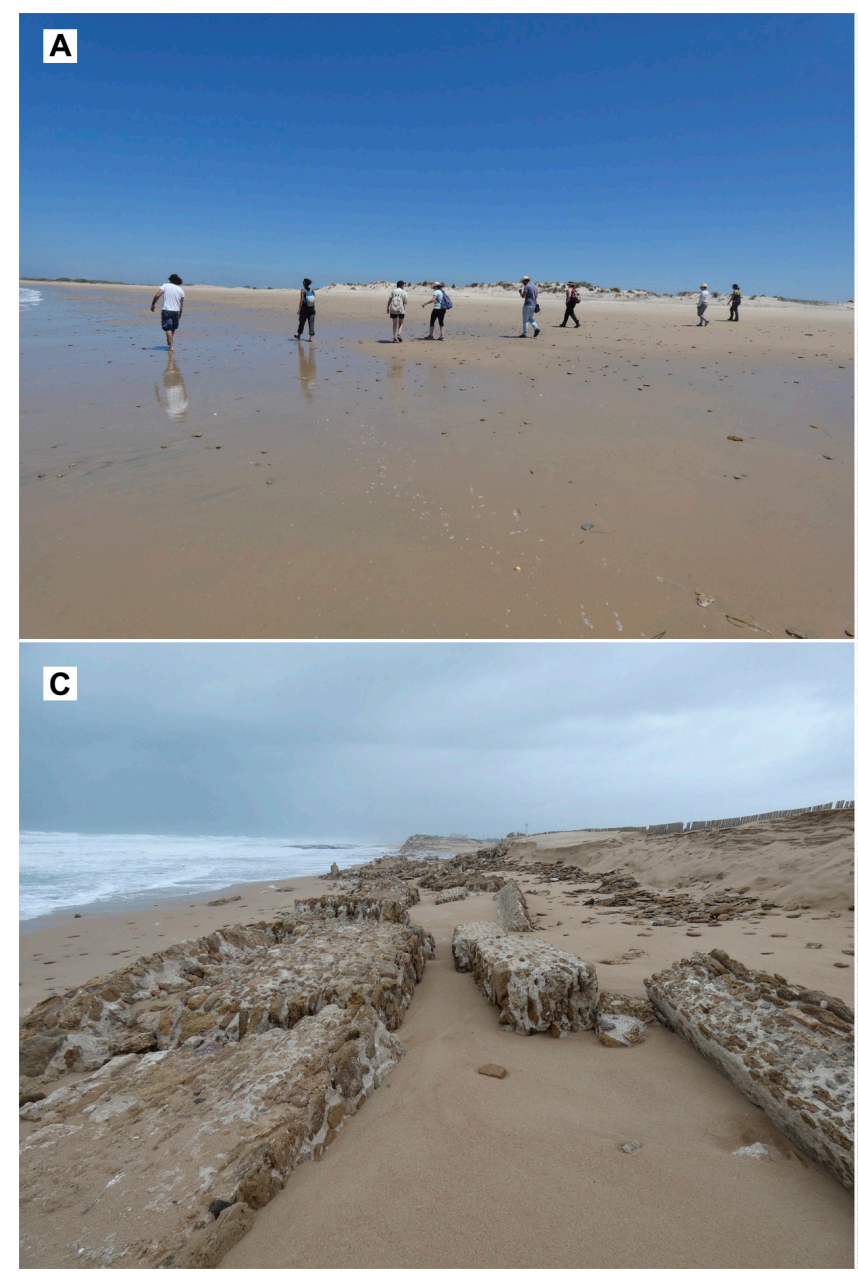

B

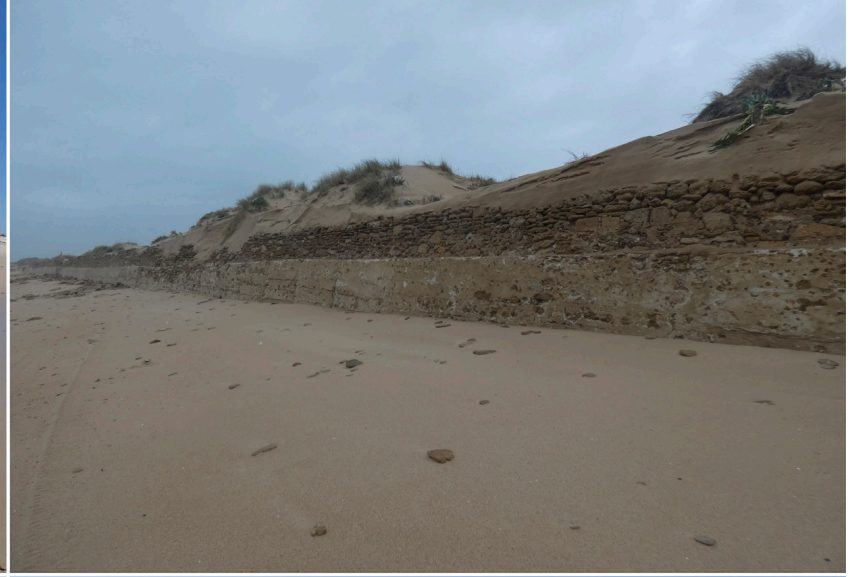

D

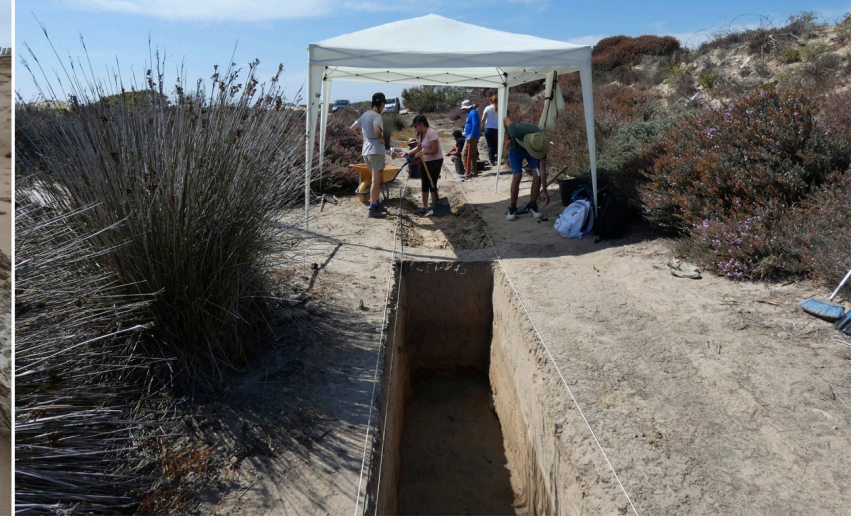

Figura 2. a) Trabajos de prospección arqueológica superficial en los terrenos militares de Torregorda; b) lienzo con más de $2 \mathrm{~m}$. de altura conservada del camino del arrecife oculto durante años en el sistema dunar y sacado a la luz tras el temporal Emma en 2018; c) restos del camino del arrecife que evidencian una destrucción traumática quizás asociada al maremoto de 1755; d) trabajos de campo desarrollados en la zona del fuerte de La Alcantarilla en julio de 2019.

La villa se asentó en un espacio extremadamente importante desde el punto de vista geoestratégico, puesto que al situarse sobre la ladera meridional del Cerro de los Mártires, desde las cotas más altas del mismo -donde se ubica el taller alfarero que analizamos en estas páginas- se controlaría toda la red de canales que se abrirían hacia el caño de Sancti Petri y que desembocarían en el entorno del templo del Hercules Gaditanus, con todas las imbricaciones político-económicas que eso implicaría. De igual forma, la red viaria terrestre tampoco hay que desestimarla pues en la cartografía histórica de época bajomedieval y moderna siempre aparece un ramal que circunda el asentamiento, por lo que no es de extrañar que dicha vía terrestre ya estuviera funcionando en época antigua.

Necesitada de un proyecto general de investi- gación, la mayoría de las intervenciones realizadas en este lugar estuvieron motivadas por rescates de restos por el avance de las obras de cantera en la segunda mitad del s. XX o por la afección parcial de los mismos por obras de urbanización o introducción de acometidas de servicios en el entorno. El estudio que sobre las ánforas manufacturadas en el taller hizo M. Beltrán (1977, 1983), definiendo las variantes morfológicas más arcaicas de la familia Dr. $7 / 11$, propició que el yacimiento se convirtiera en un referente historiográfico en el mundo de la producción anfórica en la Bética. En un último trabajo de síntesis publicado hace algunos años (Díaz et al., 2017) se desarrollan en contenido tanto las cuestiones historiográficas como el análisis en profundidad de las diferentes áreas funcionales conocidas, por lo que remitimos al mismo para su lectura y comprensión. 
Los hornos altos del Cerro de los Mártires (San Fernando, Cádiz). Nuevas aportaciones del Proyecto Arqueológico Camposoto - Torregorda
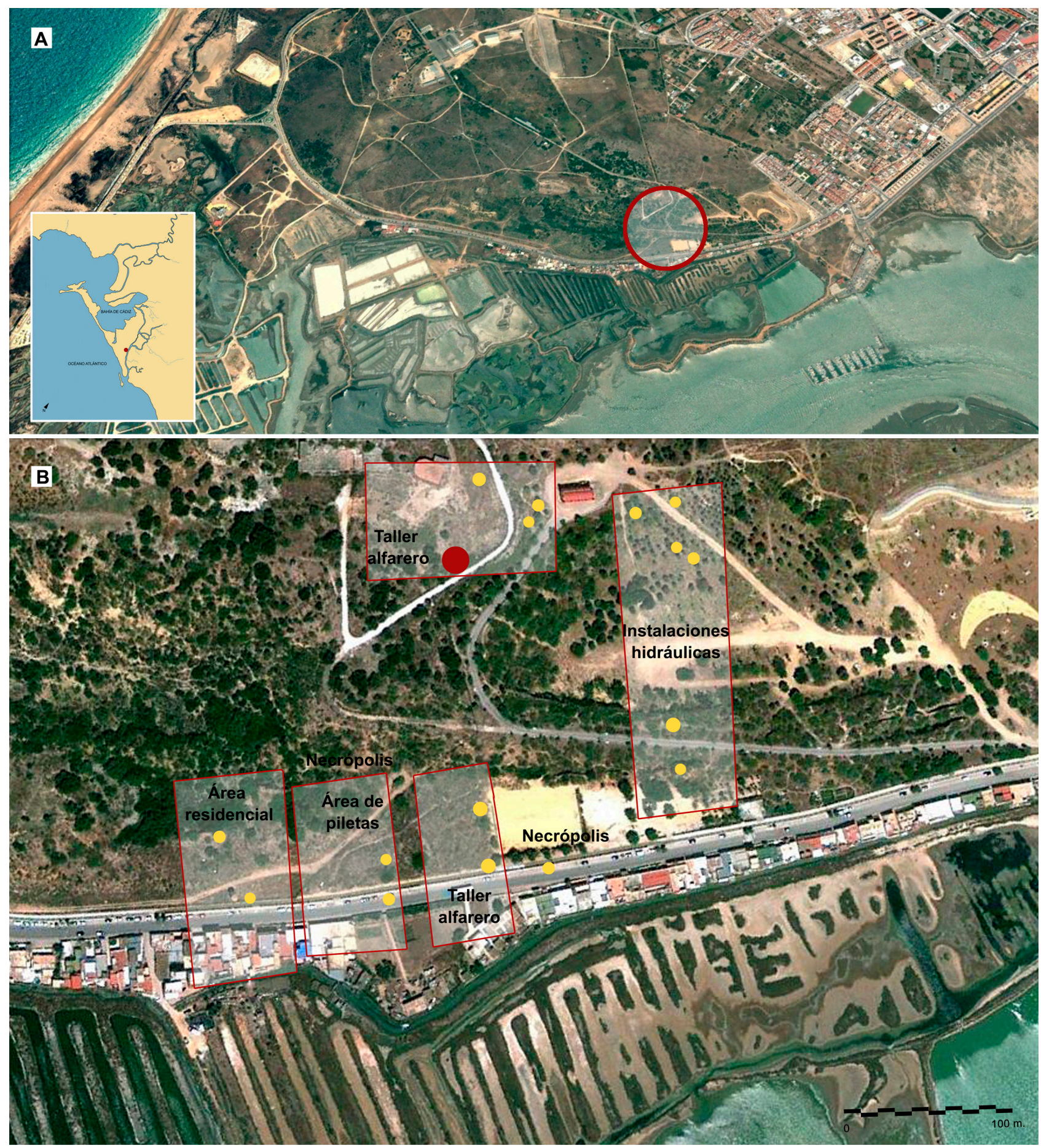

Figura 3. a) Imagen satélite del extremo sureste del T.M. de San Fernando con la indicación del yacimiento de Gallineras - Cerro de los Mártires; b) delimitación de las distintas áreas funcionales y localización de los principales hallazgos arqueológicos en este sitio. (Fuente: a partir de Díaz et al., 2017: fig. 2).

Revista Atlántica-Mediterránea de Prehistoria y Arqueología Social 22, pp. 189-207 Universidad de Cádiz 
Por ello, en estas páginas solo mencionaremos de forma genérica los espacios conocidos con el fin de contextualizar el estudio que presentamos (Figura 3b). Así, en esta zona se construyó, en un momento indeterminado del s. I a.C., un asentamiento rural tipo villa, perteneciente posiblemente a un liberto de la familia de los Iulii (Lagóstena, 2001), tal y como se ha interpretado a partir de la localización en la década de los sesenta del siglo pasado de un cipo de propiedad con la inscripción en escritura griega IOYAIOY (Figura 4a). Cuenta con una zona residencial con algunas habitaciones decoradas con suelos de mosaicos (Figura 4b), dispuestas alrededor de un patio central con pozo o aljibe. De la villa también se conocen conducciones subterráneas para transportar agua (Figura 4c) y dos zonas de enterramientos -una más lujosa perteneciente quizás a los propietarios y otra más modesta vinculada con los artesanos- (Figura 4d) (Díaz, 2018; Sáez y Díaz, 2010). El momento de apogeo se prolongó durante el s. I d.C. Aunque la villa siguió activa hasta época tardorromana (ss. IV - V d.C.), a partir de la primera mitad del s. II d.C. comenzaría el paulatino ocaso del lugar con el cierre del alfar.

En cuanto a las áreas productivas, la villa contó con distintos espacios productivos donde se llevaron a cabo trabajos de acuicultura y alfarería, entre otros. En primer lugar, mencionamos la localización de algunas piletas (Figura 5a) tanto bajo la carretera como en los terrenos militares y municipales, las cuales estaban agrupadas en torno a un patio central pavimentado que contaba, además, con un pozo. Estas balsas deben entenderse como unas piscinas alargadas que se diferencian morfológicamente de las usadas en las factorías de salazón. Tanto el suelo como sus paredes estaban revestidas con capas de hormigón impermeable, si bien algunas de ellas parece que estuvieron interconectadas por tuberías plúmbeas. Por su morfología y por la cantidad de malacofauna documentada en su interior (principalmente murícidos), se vincularon en un primer momento con una posible officina tinctoria (Corzo, 1982), si bien al no haberse intervenido con metodología reciente aún esta hipótesis no ha podido ser contrastada. En todo caso, aceptamos la hipótesis desarrollada por D. Bernal (Bernal-Casasola, 2018; Bernal-Casasola et al., 2005), para el que estas balsas podrían ser la evidencia de la existencia de un vivarium donde se llevaría a cabo la crianza de peces y moluscos. En este sentido, el gaditano Columela las describe de forma minucio- sa en uno de sus tratados (De re rustica, VIII, 1617), refrendo quizás de la existencia de éstas en el litoral gaditano, como ejemplifica también el caso del vivario localizado en el promontorium Iunonis en Trafalgar (Bernal-Casasola et al., 2011).

En relación a la producción alfarera, hay que resaltar cómo previo a la construcción del asentamiento rústico romano, existió un taller en época púnica que estaría en funcionamiento desde los ss. V-IV a.C. hasta décadas antes a la erección de la villa (Sáez et al., 2003). A partir del s. I a.C., anexo al complejo villático, y como sucedió en muchos de los asentamientos rurales que jalonan el litoral de la isla de San Fernando (Díaz et al., 2004), se instalaron dos talleres cerámicos; uno situado en la parte alta del cerro y otro inmediato al posible vivero. Como dijimos en párrafos anteriores, debido a las labores de cantería y urbanización del entorno, los hallazgos arqueológicos se fueron sucediendo a lo largo de la segunda mitad del s. XX, aunque también provocaron la desaparición de algunos hornos. Actualmente en la zona alta del Cerro se conoce al menos un fornax, descubierto por el Grupo local de Arqueología Geryon en los años setenta (Figura 5b) y diagnosticado en 2017 gracias al Proyecto Arqueológico TorregordaCamposoto, que es el objeto de estudio principal en estas páginas. Por su parte, en la parte baja en Gallineras, de las siete piroestructuras que pudieron existir, se conserva parcialmente descubierto uno con pilar central para sustentar la parrilla (Figura $5 \mathrm{c}$ ). Además, se han localizado los vertederos donde se depositaban las cerámicas defectuosas y los almacenes -al aire libre- donde se guardaban las ánforas antes de su comercialización, lo que ha favorecido el conocimiento de las distintas piezas que se manufacturaban allí. Así, en esos hornos situados en la parte baja del yacimiento debieron fabricarse principalmente ánforas, siendo segura la producción de Dr. $7 / 11$, y probablemente otro tipo de envases como Dr. 1C, Dr. 12, Haltern 70 (Sáez et al., 2003) y Beltrán IIA (Lagóstena, 1996). Además, y de manera complementaria en los hornos de Gallineras también hubo cabida para la producción de material latericio (ladrillos cuadrangulares, romboidales o semicirculares), tégulas o ímbrices, así como cerámicas comunes (platos, jarras, cuencos o pequeños dolia). En lo que respecta al taller emplazado en lo alto del cerro, también debieron fabricarse ánforas -Dr. 7/11 y probablemente Haltern 70- (García, 1998), junto con otros objetos más sutiles como cerámicas co- 
Los hornos altos del Cerro de los Mártires (San Fernando, Cádiz). Nuevas aportaciones del Proyecto Arqueológico Camposoto - Torregorda

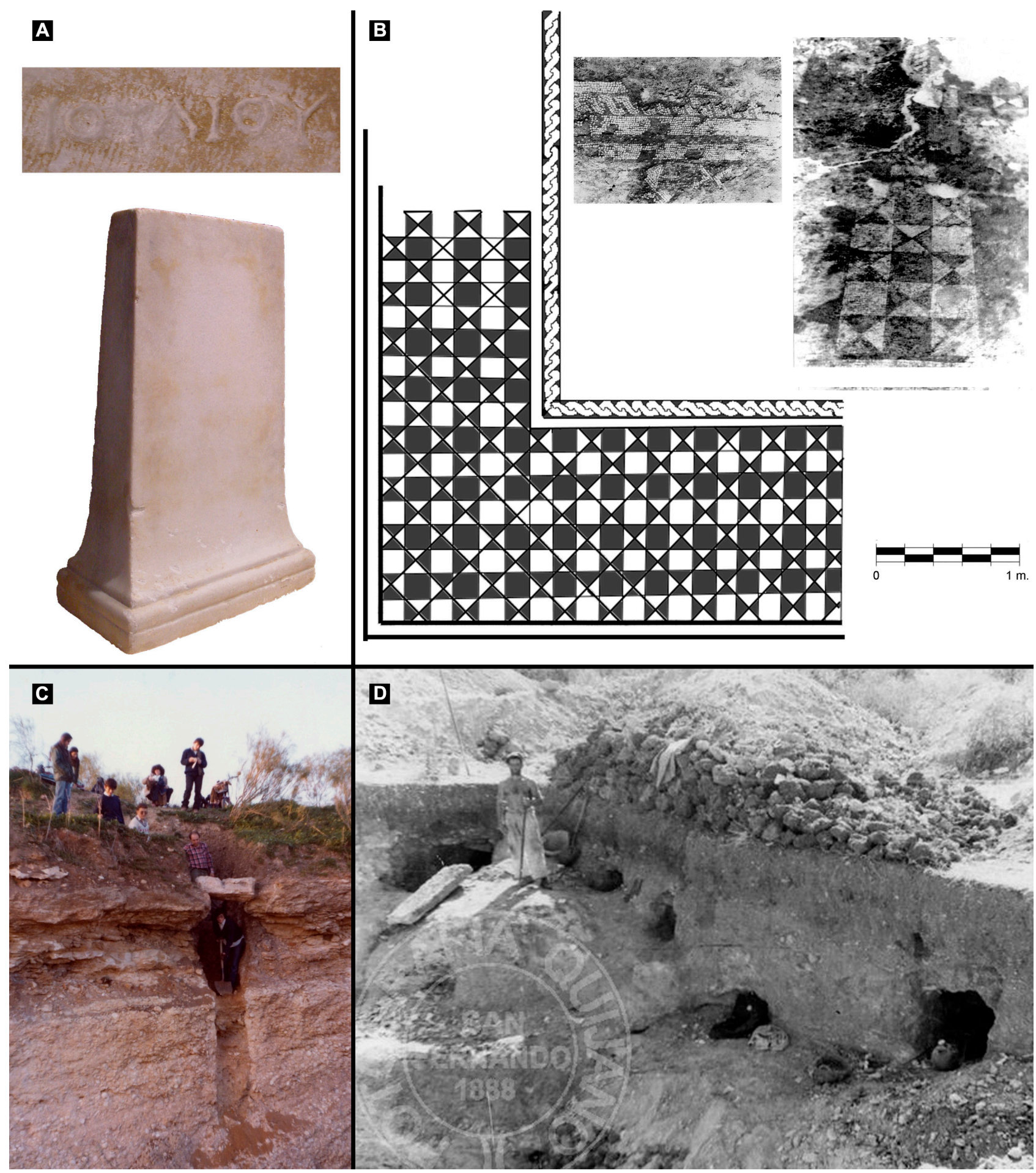

Figura 4. Hallazgos arqueológicos en el yacimiento de Gallineras - Cerro de los Mártires:

a) Cipo de mármol; b) restos de mosaico y croquis de su diseño; c) pozo de conducción hídrica; d) tumbas de la necrópolis afectada por las labores de cantera. (Fuente: a partir de Díaz et al., 2017: figs. 3c, 4a y 7e; y Díaz, 2018: fig. 7c). 

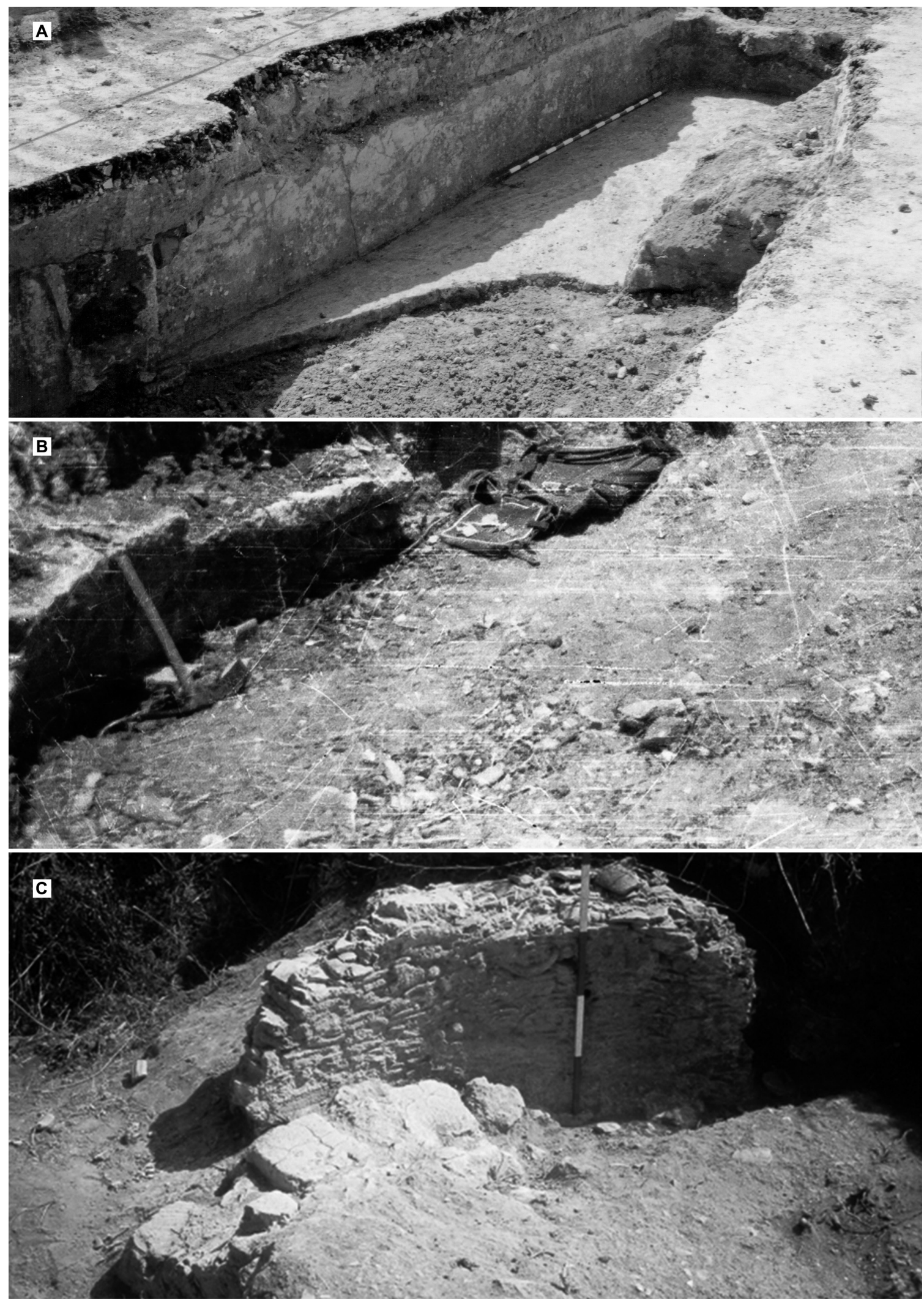

Figura 5. Hallazgos arqueológicos en el yacimiento de Gallineras - Cerro de los Mártires: a) piletas localizadas bajo la carretera; b) horno del taller de la zona alta del Cerro de los Mártires; c) horno del taller de la zona baja de Gallineras. (Fuente: a partir de Sáez y Díaz, 2010: figs. 8.9 y 8.10$)$. 
munes de mesa y cocina (jarras, cuencos, platos, tapaderas, ollas,...), lucernas (con el sello CIUNDRA o IUNDRA asociado al figulus norteafricano Caivs Ivnivs Dracvs - Bernal-Casasola, 1995; Corzo, 1982-) (Figura 6a); así como terracotas (Figura 6b) e imitaciones locales de cuencos y fuentes de cocinas africanas (Sáez et al., 2017). También destaca la manufactura de sítulas con apliques de rostros barbados dionisiacos (Sáez et al., 2011) (Figura 6c) cuyos ejemplares completos se han documentado en el testaccio haliéutico de Gades (Figura 6d) (Bernal et al., 2019).

\section{Los trabajos arqueológicos acometidos en el 2017 en el horno H-1}

Entre finales del mes de marzo y comienzos de abril de 2017 se ejecutó una campaña de intervención arqueológica en los terrenos militares del acuartelamiento de Camposoto -agradecemos a los miembros del equipo de investigación, F. Ghersi, F. Cerezo, J. Ma Aceytuno y S. Gómez, su implicación en los trabajos de campo realizados durante la campaña de intervención arqueológica de 2017-. En relación al proyecto de investigación, la zona de actuación se emplazó en la denominada como zona A1, que se corresponde con la parte más elevada del Cerro de los Mártires. Allí se llevaron a cabo trabajos de prospección superficial, así como un sondeo en la ladera que mira hacia el caño de Sancti Petri, inmediato al cercado que separan los terrenos militares de los municipales (Figura 7a). Para la ubicación en este punto exacto del sondeo, fue crucial la intervención de F. Ghersi, miembro de nuestro equipo de investigación que había participado décadas atrás en los trabajos de exploración del citado horno. El corte practicado abarcó una superficie de $6 \mathrm{~m}^{2}$, con unas dimensiones de $3 \mathrm{~m}$ sentido noroeste-sureste por $2 \mathrm{~m}$ sentido suroeste-noreste y se situó junto al vertedero cerámico que aún es visible en superficie (Figura $7 \mathrm{~b} \mathrm{y} \mathrm{c).} \mathrm{El} \mathrm{objetivo} \mathrm{principal} \mathrm{de} \mathrm{la} \mathrm{campaña} \mathrm{era} \mathrm{la}$ verificación de la existencia de la estructura. Con los permisos de intervención que poseíamos era inviable excavar en toda la extensión y agotar la secuencia estratigráfica, por lo que la excavación se redujo, como decíamos, a confirmar que dicha estructura se trataba de un horno asociado con el taller cerámico. Por este motivo, aunque los resultados han sido positivos no se pudo completar la exhumación integral de la piroestructura. Pese a ello, se han obtenido resultados que vienen a ofre- cer novedades con respecto a lo que se conocía de los hornos altos del Cerro de los Mártires.

Los restos localizados se corresponde con el cierre perimetral del contorno sur - suroccidental de la cámara de combustión, así como el enlace de ésta con el praefurnium (Figura 8a); extendiéndose el fornax más allá de los perfiles noreste, sureste y noroeste del corte estratigráfico practicado.

Sabemos que la piroestructura se construyó realizando una fosa en unas gredas que configuran la base geológica donde se insertó el horno. Estas gredas geológicas eran visibles en superficie en distintas zonas del entorno, evidenciando que no se trata de un caso aislado y, por tanto, el alfar se asentó sobre un afloramiento importante de arcillas / gredas aptas para el modelado y su transformación posterior en cerámicas, cuyas características compositivas se conocen por otros trabajos (García et al., 2019). Individualizadas como UE 106 se documentaron exiguamente en las esquinas oeste y sur del sondeo, siendo característica una compactación muy elevada y una granulometría muy fina. La boca del corredor de entrada estaba orientada hacia el este, situándose entonces en la zona inferior de la ladera, por lo que la fosa de inserción del horno tenía una mayor potencia en la zona posterior del mismo. Tras la excavación de la fosa con la morfología del horno, el negativo resultante generado en las gredas se repelló o enfoscó con una capa gruesa de unos 40 - $50 \mathrm{cms}$ de arcillas de tonalidad naranja (UE 105), estéril de material (Figura 8b). Esas arcillas no funcionaron como pared interna del horno, sino que a ellas se le adosó un murete perimetral construido con adobes (Figura 8c), de los que se han observado dos módulos; uno más grande con una longitud / anchura / altura de $32 \times 24 \times 5$ cms, y otra menor con unas medidas de $16 \times 12 \mathrm{x}$ $5 \mathrm{cms}$, teniendo entonces una relación entre ambos de $1 / 2$. Hasta donde se pudo profundizar en la excavación interna de la cámara de combustión, se atestiguó una altura / potencia conservada de unos $\pm 60 \mathrm{cms}$ de alzado, con un máximo de seis hiladas, presentando en muchos de esos adobes evidencias de termoalteración.

El buzamiento / inclinación de la actual ladera que se ha mencionado ha tenido también como consecuencia el diferente grado de conservación de la piroestructura, estando mucho mejor conservada la zona posterior y más arrasado el praefurnium. En este sentido, tanto el enfoscado de gredas como el murete de adobes presentaron 


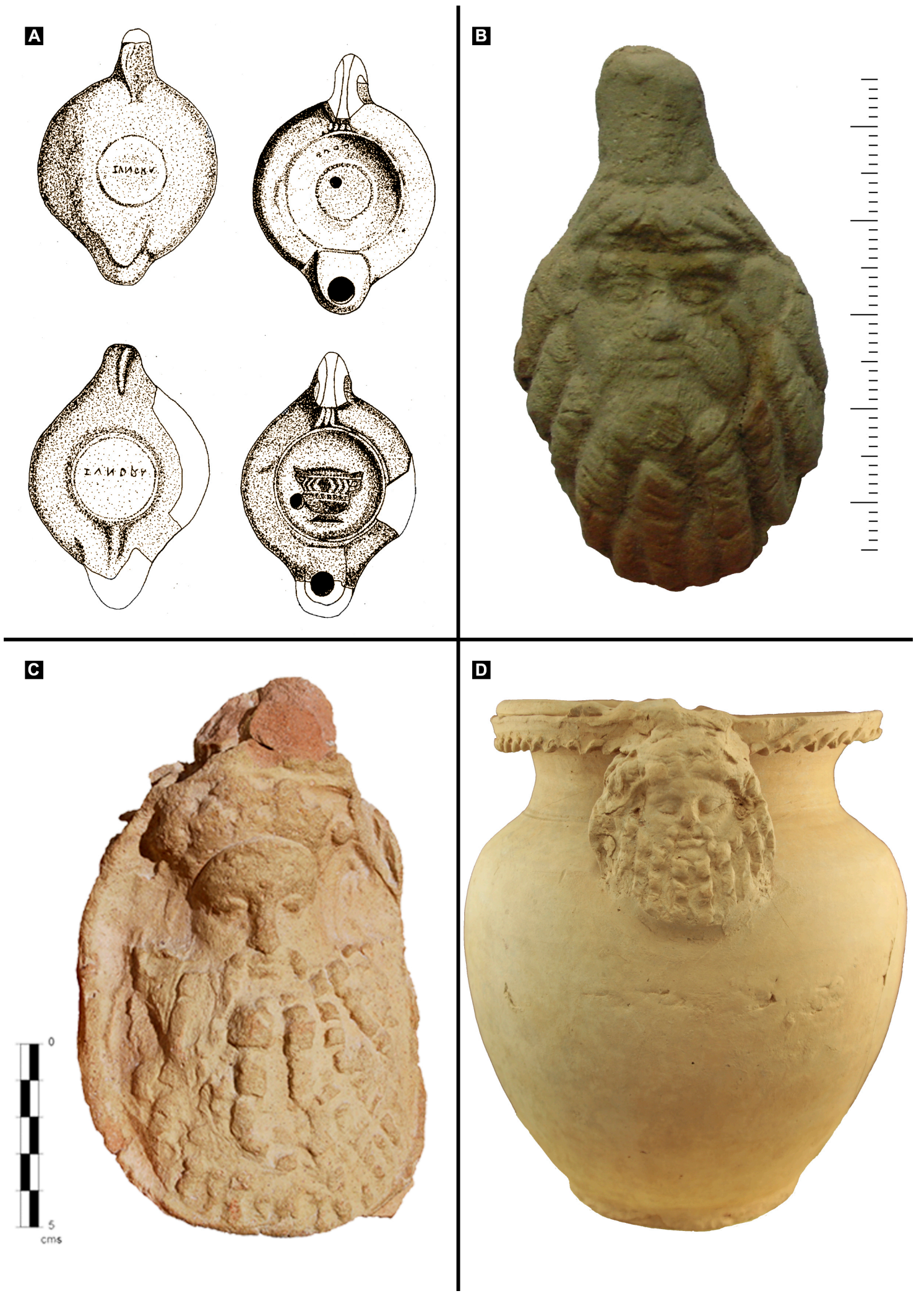

Figura 6. Producción del taller de la zona alta del Cerro de los Mártires. a) Lucernas; b) positivo de un molde de un aplique antropomorfo; c) aplique de rostro barbado; d) sítula crateiforme documentada en el Olivillo manufacturada en el taller del Cerro de los Mártires. (Fuente: a partir de Díaz et al., 2004: figs. 3.1, 3.3; Sáez et al., 2011: fig. 4; Bernal et al., 2019: fig. 2). 
Los hornos altos del Cerro de los Mártires (San Fernando, Cádiz). Nuevas aportaciones del Proyecto Arqueológico Camposoto - Torregorda

una acusada diferencia en su cota de aparición entre la parte posterior del horno y la conexión de la cámara de fuego con el praefurnium, siendo ésta de aproximadamente unos $70 \mathrm{cms}$. Desgraciadamente, por ese estado de conservación, en el interior de la pared del fornax no se apreciaron signos de la existencia de posibles arcos de sustentación de la parrilla, los cuales quizás debieron disponerse a una mayor altura.
Aunque por las características del sondeo, no se ha podido documentar en planta toda la extensión del horno, éste debió tener una morfología piriforme con ninguna discontinuidad arquitectónica entre praefurnium y cámara de fuego, salvo la lógica del desarrollo más lineal del corredor de entrada y el desarrollo más circular de la cámara de combustión. Además, por ese progreso radial del perímetro de la cámara de combustión, pen-
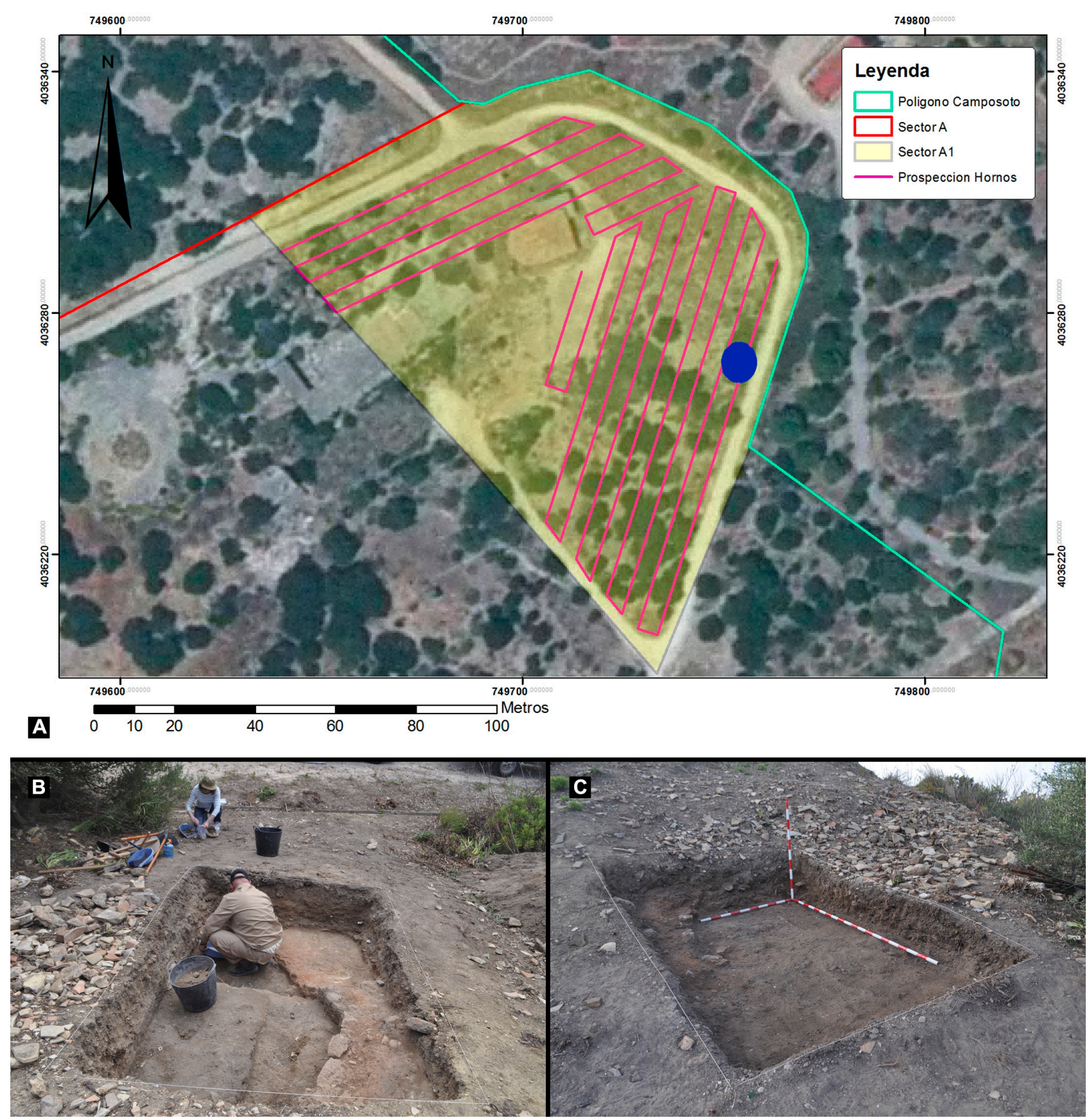

Figura 7. a) Vista satélite del sector A1 de Camposoto con la señalización del trazado de la prospección arqueológica superficial y la situación del sondeo estratigráfico realizado; b) proceso de excavación del horno; c) detalle del emplazamiento del corte junto a la escombrera documentada en superficie. 

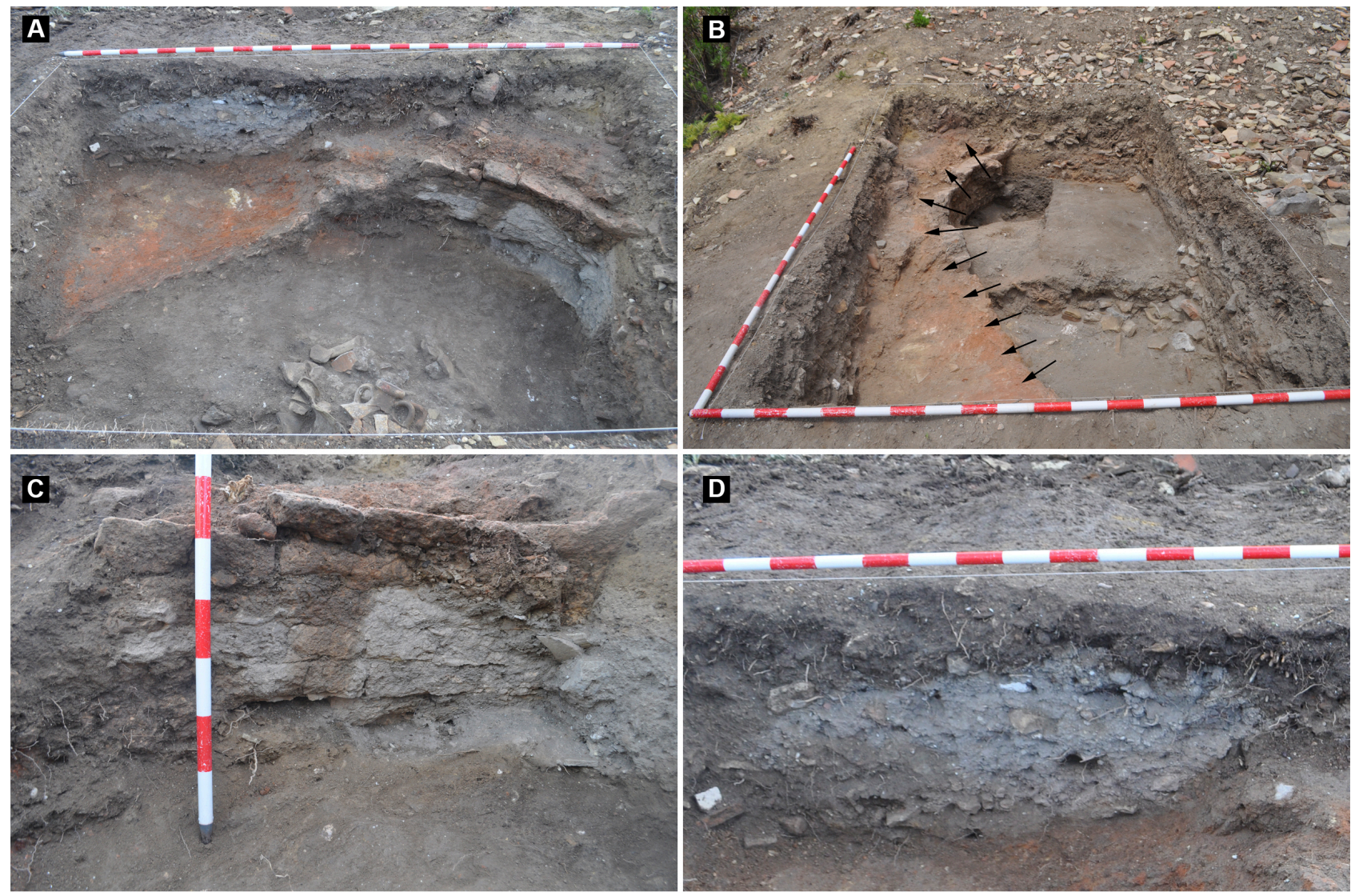

$\mathbf{E}$

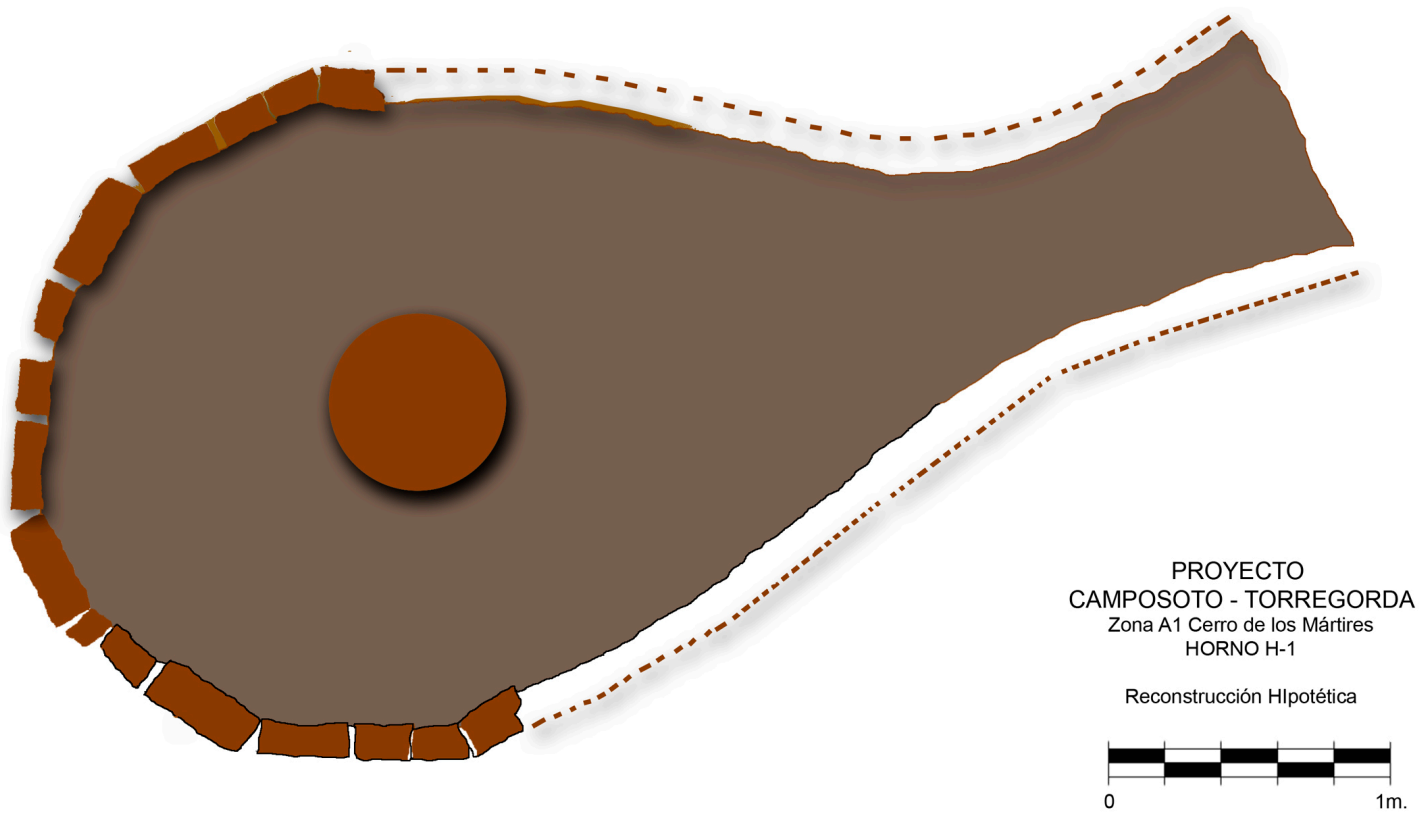

Figura 8. a) Horno H-1: vista general del sondeo con los restos parciales del horno exhumado (a); b) detalle del horno desde el sur con indicación de las arcillas que repellaron la fosa de construcción; c) detalle del alzado del murete perimetral de adobes; d) detalle del perfil oriental con los restos de la bolsada de cenizas; e) planta completa hipotética del horno H-1 a partir de los restos documentados. 
samos que su punto central -y por tanto el pilar central de haber existido- debió situarse en el entorno del perfil NE del corte. A la profundidad alcanzada, tampoco documentamos evidencias de restos conservados del citado posible pilar, por lo que el horno $\mathrm{H}-1$ podríamos vincularlo o bien con el tipo IA de Cuomo di Caprio o 7B de Coll (Coll, 2008; Cuomo, 1972, 2007), o bien con el tipo B1 de Coll de finalmente no existir ese elemento central de sustentación de la parrilla. Por otro lado, desde la pared interna de la cámara de fuego hasta el epicentro del fornax, existe una distancia de $1,20 \mathrm{~m}$, lo que nos permite hipotetizar sobre un posible diámetro del horno en torno a 2,40 m ( Figura 8e).

En lo que respecta a los estratos de amortización, habría que diferenciar tres tipos; los vinculados al proceso de relleno del interior de la estructura, los documentados al exterior de la misma y los asociados al proceso de génesis de la superficie actual. En este último caso, el estrato superficial (UE 100) que cubría la estratigrafía plenamente romana, debemos vincularlo con la intervención de los años setenta del s. XX, cuando se practicó una pequeña limpieza arqueológica en la zona, se localizó el murete de cierre del horno y posteriormente se procedió a su tapado con las mismas tierras exhumadas. Entre el material documentado se recuperaron gran cantidad de restos cerámicos de época romana entre los que destacamos ánforas Dr. 7/11, Beltrán IIb, sigilata altoimperial, ARSW A, cerámicas de paredes finas, cerámicas comunes -mayoritariamente lebrillos-, así como cerámicas africanas de cocina y utensilios de cocina (Figura 9). Aunque el porcentaje mayoritario de cerámicas fue de cronología romana, junto a ésta aparecieron elementos contemporáneos que nos permitieron fechar el estrato en ese momento y vincularlo con dicha intervención.

Los niveles documentados al exterior del horno se dispusieron sobre los restos ya amortizados del mismo, extendiéndose de forma puntual también unos centímetros por el interior de la cámara de fuego, depositándose sobre los niveles de cubrición de dicha cámara. La naturaleza de los dos estratos individualizados (UUEE 104 y 107), caracterizados por estar conformados por cenizas, debemos vincularla con procesos de limpieza de estructuras de combustión en la zona. Las dos manchas, una situada en la esquina sur del sondeo (Figura 8d) y otra anexa a la parte posterior del horno, aparecieron limpias de materiales, alcanzando ambos una potencia aproximada de unos 30-40 cms. La existencia de vertidos puntuales de cenizas en un contexto alfarero es algo habitual que se puede vincular con la limpieza de las piroestructuras (Díaz, 2008: 102-106). Sin embargo, el hecho de que las UUEE 104 y 107 corten parcialmente a los niveles de amortización del interior del horno es de suma importancia, puesto que estos últimos se generaron cuando $\mathrm{H}-1$ ya estaba amortizado. Por tanto, los dos vertidos de cenizas no pueden relacionarse con la limpieza puntual de este horno durante su periodo de actividad, sino que debemos vincularlos entonces con las actividades que se realizaron en el entorno con otras estructuras alfareras activas tras el abandono de $\mathrm{H}-1$.

Por último, en lo que respecta al proceso de colmatación interna de la estructura fornácea, hay que insistir de nuevo en que no se alcanzó la solería de la cámara de fuego a pesar de haber rebajado unos $75 \mathrm{cms}$ con respecto al punto de conservación más elevado del murete perimetral. Se individualizaron tres niveles (UUEE 101, 102 y 103) que fueron superponiéndose uno a otro. El inferior (UE 103) tenía como característica la presencia dentro de la matriz arenosa, como inclusiones de nódulos de arcilla y de cal, éstas de mayor tamaño. De este estrato se pudieron rebajar unos $20 \mathrm{cms}$ donde, entremezclado con el sedimento, aparecieron gran cantidad de fragmentos cerámicos y constructivos, habiéndose vinculado esta UE 103 con un vertido puntual efectuado en el interior del horno, una vez que éste había caído en desuso. Entre el material recuperado podemos destacar la presencia residual de ánforas de producción autóctona Dr. 7/11 y Beltrán IIa y Beltrán IIb, así como ánforas importadas (Africana IIA) y restos de dolia, un cuenco Hayes 9B en ARSW A, una marmita Hayes 197 en africana de cocina, un opérculo y un borde de una jarra de cerámica común, cerámicas de cocina -ollas-, así como fragmentos de ímbrices, restos de pintura mural y casi una veintena de fragmentos de malacofauna (Figura 10). Por su parte, la UE 102 se caracterizó por la presencia entremezclada con las arenas que conformaban su matriz de restos de adobes disgregados, fruto de la descomposición de las paredes de la piroestructura. Entre el material documentado en su interior destacamos la mayoritaria presencia de fragmentos de cerámica común y de cocina, algunos fragmentos de lucerna -ninguno con sellos propios del taller-, ARSW C y algunos 

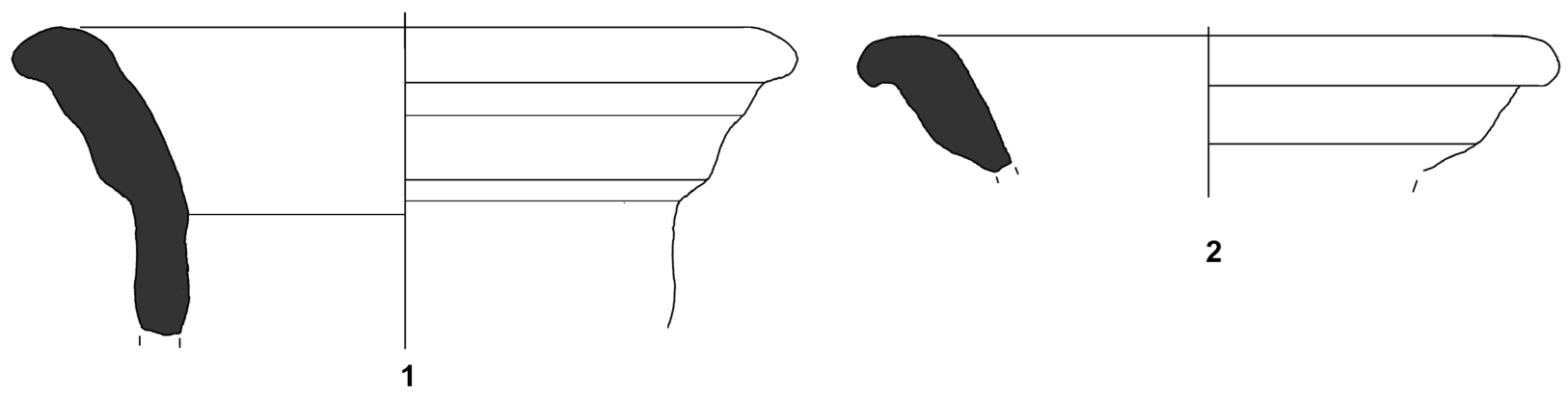

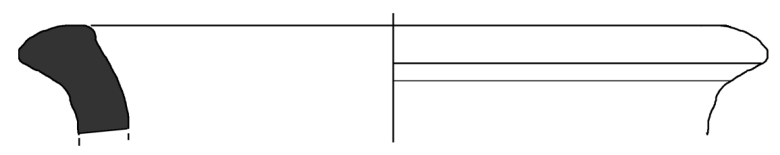

3

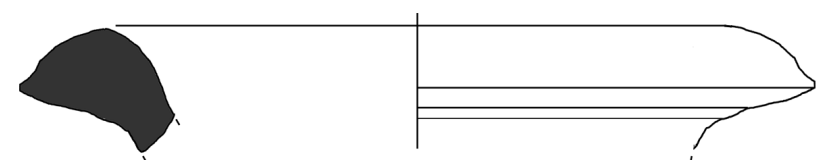

4
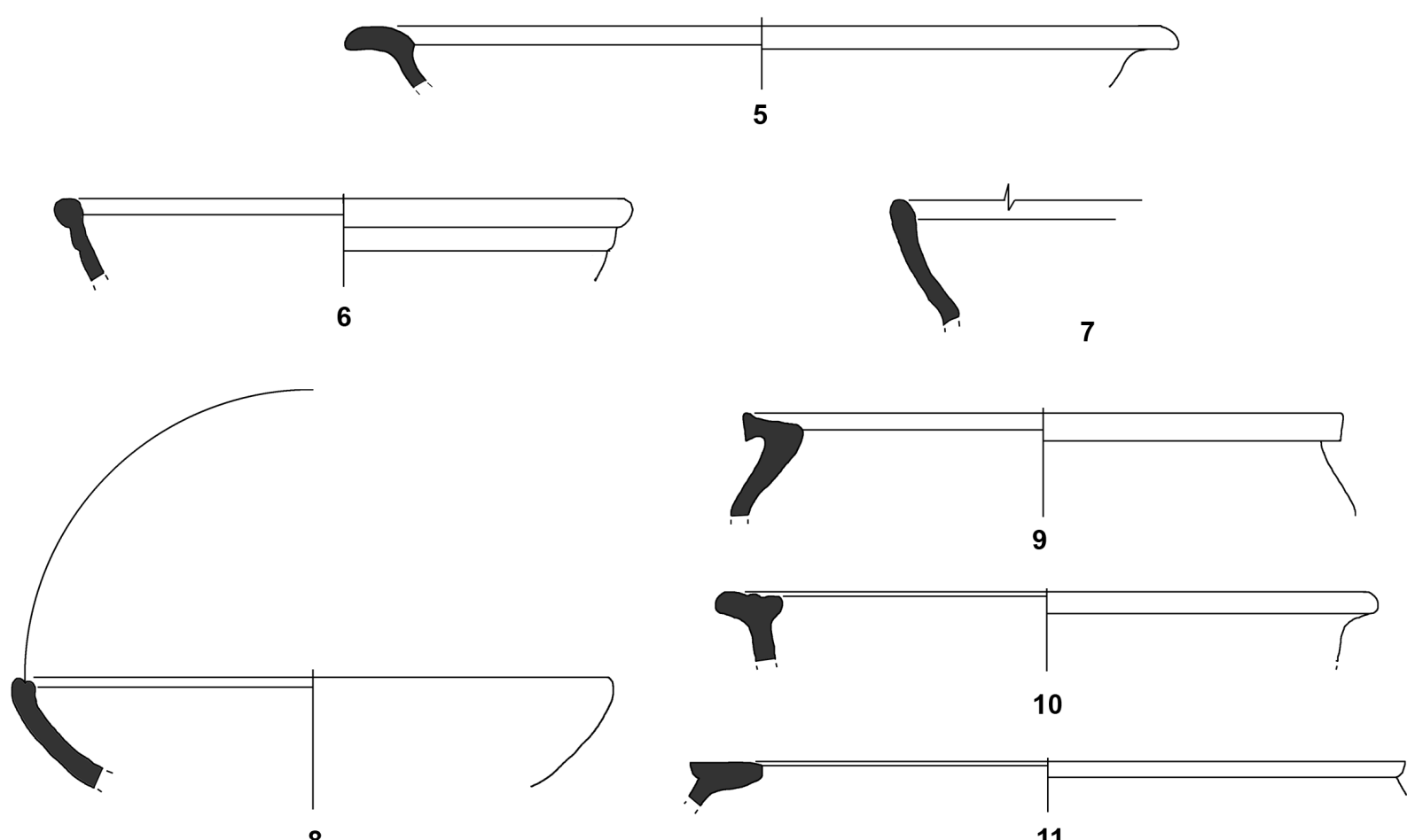

11

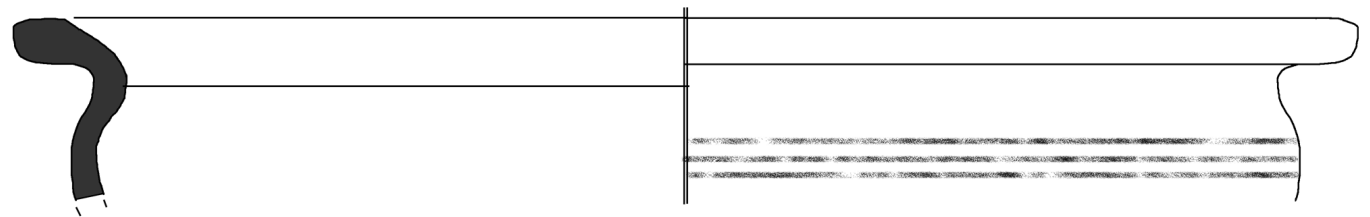

12

Figura 9. Materiales cerámicos procedentes de la UE 100 superficial: ánforas Dr. 7/11 (1, 2); ánforas Beltrán IIb (3 y 4); borde de TSH Hispánica 35/36 (5); borde de ARSW A Hayes 9b (6); borde de cerámica africana de cocina Hayes 23 (7); formas abiertas (8) y cerradas (9-12) de cerámicas de cocina. 
bordes de africanas de cocina (plato en Hayes 23 y marmita en Hayes 197), dolia y algún borde de ánfora Dr. 7/11 (Figura 11). Asimismo, se individualizaron restos de ladrillos, tégulas e ímbrices, un borde de vidrio y una cuenta de pasta vítrea, una aguja y una bisagra en hueso trabajado, así como diversos fragmentos de fauna terreste y malacofauna (conchas de bivalvos y murícidos). Por último, un contexto material similar se recuperó en la UE 101, que constituía el último nivel de relleno de la piroestructura, con algunas paredes de sigilatas claras, africanas de cocina (Hayes 23 y 196), ollas de fondo plano, jarras con el borde trilobulado en común o un pivote de ánfora africana. Aunque en los niveles de amortización aparecen cerámicas más antiguas (como los bordes de ánforas locales Dr. 7/11 o Bel. IIA o los fragmentos de lucernas o algún otro aislado de sigilata altoimperial), el elenco cerámico de los tres niveles nos permite trasladar el momento de génesis de este vertido en un momento indeterminado entre la segunda mitad del s. II d.C. y el s. III d.C.

\section{Conclusiones y perspectivas de futuro}

Los trabajos arqueológicos de comprobación en la zona alta del Cerro de los Mártires han cumplido con el objetivo principal propuesto, ya que la ubicación del sondeo fue acertada y se pudo constatar la existencia de una estructura y asociarla con un horno cerámico vinculado con el taller alfarero situado en la zona. De dicha piroestructura se ha avanzado en su caracterización arquitectónica con una planta piriforme y con paredes perimetrales de adobes, muy diferente por tanto del horno conservado en el taller de la zona de Gallineras. De igual forma, sabemos que el horno fue abandonado y rellenado con vertidos de distinta naturaleza (¿reutilizado como área de vertidos?) durante la segunda mitad del s. II d.C. o la centuria siguiente.

En cuanto al material, no se han documentado en el interior del horno restos de piezas deformes. No obstante, las pastas cerámicas de muchos de los elementos recuperados nos indican su procedencia local confirmando la producción cerámica en el taller de la zona de Cerro de los Mártires de ánforas Bel. IIA, Dr. 7/11, morteros, lebrillos, y otra serie de cerámicas comunes. En esta ocasión no hemos documentado fragmentos vinculados con las famosas lucernas con los sellos de CIVNDRAC.
Por último, también quisiéramos mostrar nuestras esperanzas en seguir profundizando en la investigación en esta zona del yacimiento de Gallineras - Cerro de los Mártires, gracias a la continuación de futuros trabajos arqueológicos en la zona que venga a darnos luz sobre los siguientes asuntos:

- Conocer la planta completa del horno H-1 y confirmar que nos encontramos ante un horno del tipo IA de Cuomo di Caprio con pilar central como pensamos.

- Poder determinar las características constructivas del horno $\mathrm{H}-1$, respondiendo a interrogantes actuales como cuál fue el sistema de sustentación de la parrilla, o como se desarrolló el praefurnium.

- Fijar la fecha de construcción del horno H-1. Aunque en el mundo romano existen ejemplos de hornos de planta piriforme y el uso de muretes de adobes también fue un recurso usado para la construcción de las paredes internas de este tipo de estructuras en varias zonas del Imperio, ambas características son rasgos antiguos en la tradición fornácea de la bahía de Cádiz, vinculándose a las estructuras de tradición púnica - tardopúnica, siendo muy raro -por no decir inexistente- su uso en hornos de cronología romana (Díaz y Bernal, 2017). En las páginas iniciales pusimos de relieve la constatación durante el control de movimientos de tierra en la zona baja del yacimiento de una fase púnica previa a la construcción de la villa y del alfar anexo (Sáez et al., 2003). Es cierto que en la intervención de 2017 no ha aparecido ningún fragmento de esos momentos, pero hasta que no se acometa la intervención global del horno y se documenten los niveles basales del mismo, no podremos asegurar con rotundidad que se trate de un horno de cronología romana con esas reminiscencias tecnológicas del pasado en cuanto a su factura, dejando por el momento abierta también la hipótesis de una construcción del mismo con anterioridad a finales del s. I a.C., que sería la fecha aproximada de arranque del taller romano.

- Poder conocer si junto al horno H-1 existe otra piroestructura, tal y como indicaban las informaciones referentes a los trabajos arqueológicos desarrollados a inicios de la década de los setenta del s. XX o si alrede- 

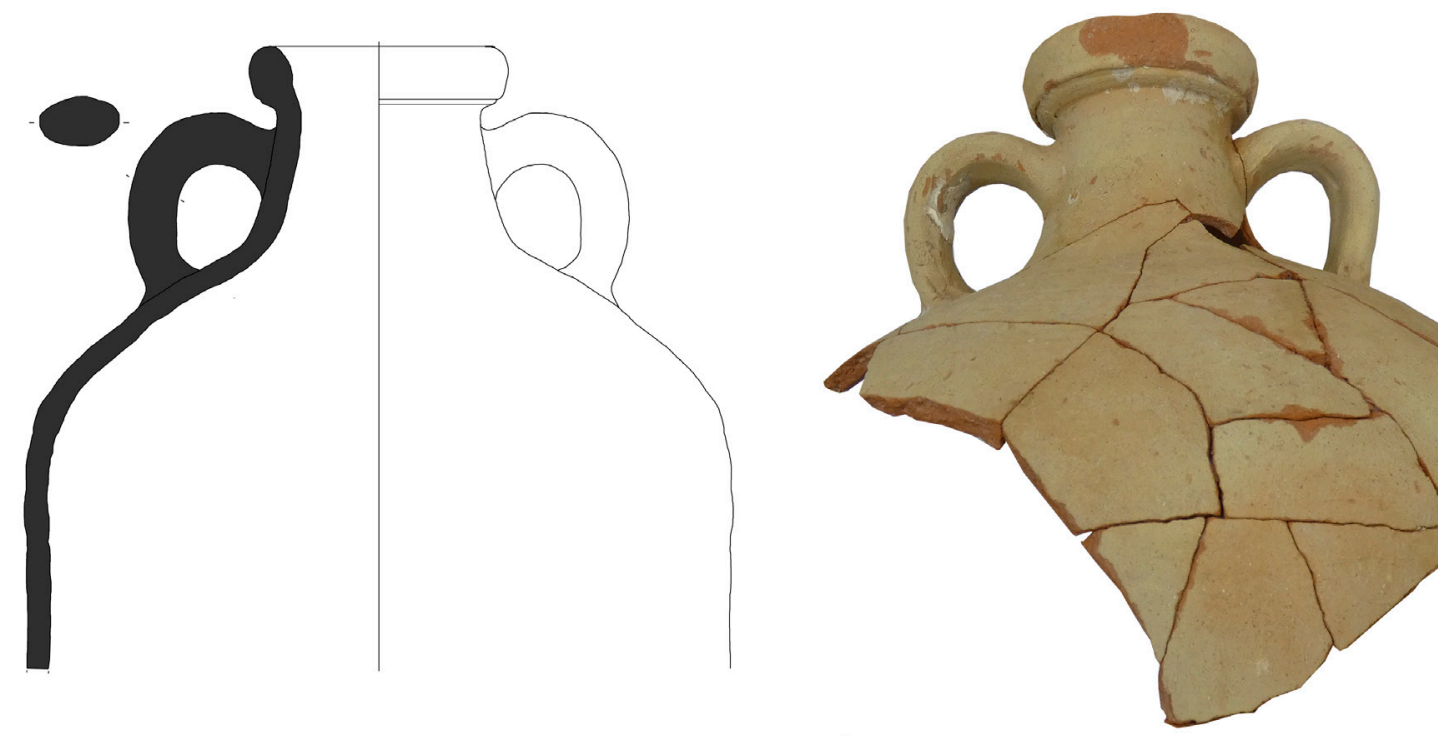

1
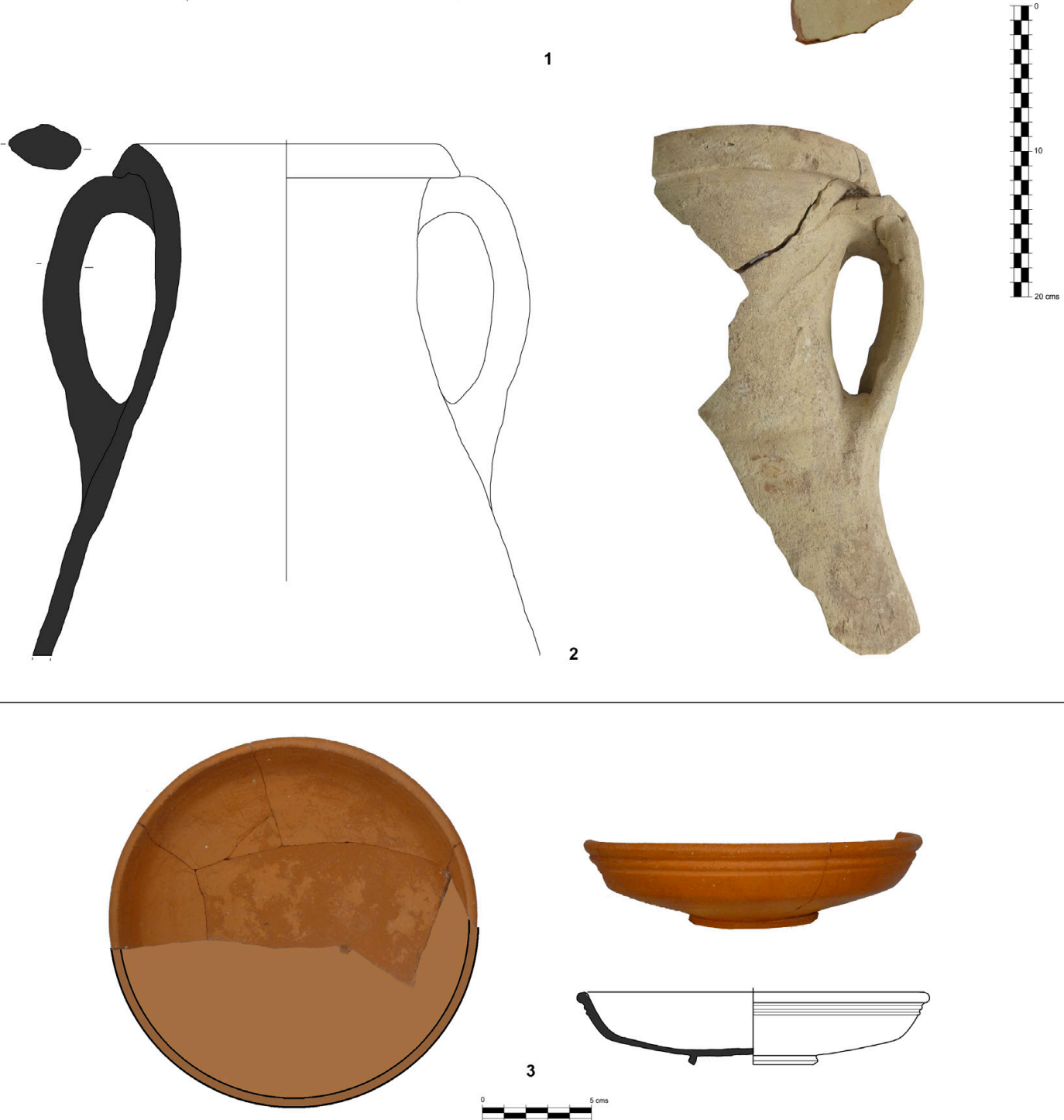

Figura 10. Materiales cerámicos procedentes de la UE 103: tercio superior de ánfora Africana IIa (1); tercio superior de ánfora Beltrán IIa (2); cuenco en ARSW A Hayes 9b (3). 

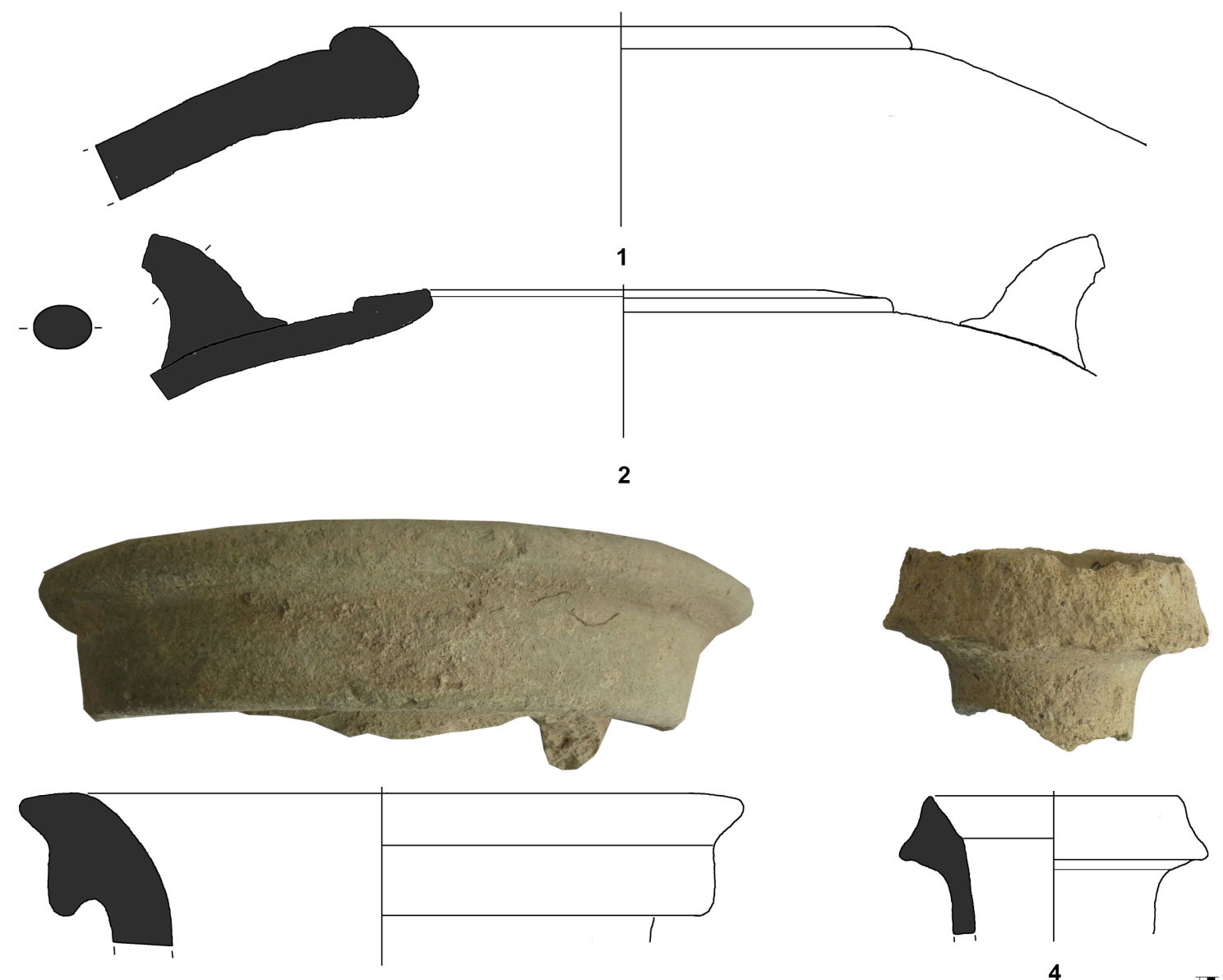

3

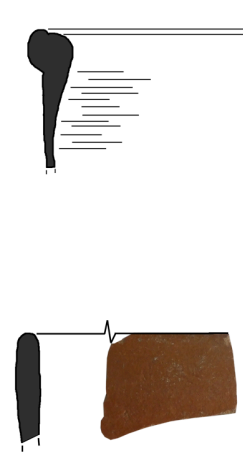

8

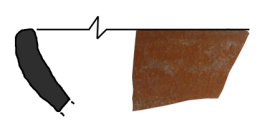

10

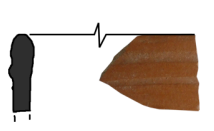

9

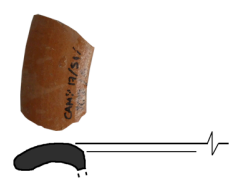

11

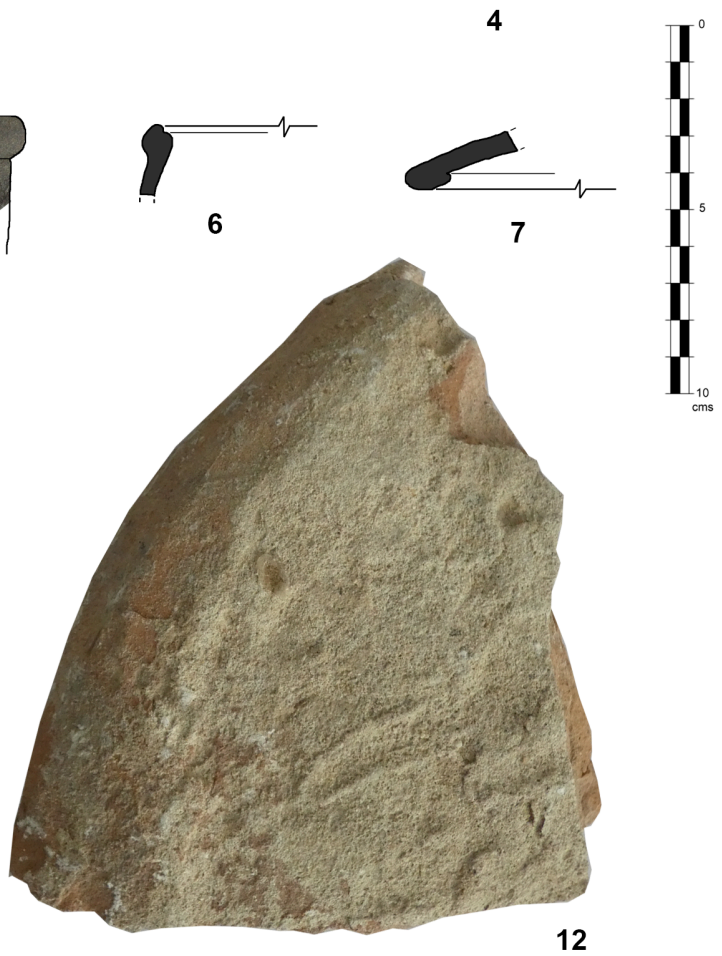

Figura 11. Materiales cerámicos procedentes de la UE 104: bordes de dolia (1 y 2); borde de ánfora Dr. 7/11 (3); boca de jarra en cerámica común (4); borde de olla en africana de cocina Hayes 197 (5-6); borde de tapadera en africana de cocina Hayes 196 (7); fragmentos de bordes en ARSW C (8-11) y ladrillo de cuarto de círculo (12).

Revista Atlántica-Mediterránea de Prehistoria y Arqueología Social 22, pp. 189-207

Universidad de Cádiz 
dor del área de producción se establecieron y conservan -más allá del área de vertidos diagnosticada junto al horno- otros espacios funcionales vinculadas con el taller (piletas de tratamiento de la materia prima, áreas de torneado y modelado, almacenes, etc...).

- Por último, establecer una cronosecuencia estratigráfica a partir de la excavación del área de vertidos existente en la zona que permita determinar las distintas fases de actividad de este complejo alfarero emplazado en la zona alta del Cerro de los Mártires.

\section{Agradecimientos}

El presente trabajo se ha elaborado en el marco del Proyecto de Investigación autorizado por el Ministerio de Defensa y el Ministerio de Cultura (Ref. SGPPH/ECV/msn) denominado "Proyecto Arqueológico de la zona de Camposoto-Torregorda, San Fernando (Cádiz)", dirigido por la Dra. Alicia Arévalo y el Dr. José Ramos, Universidad de Cádiz, estando también vinculado al desarrollo del proyecto "ARQ-ANALYTICs. Analíticas y Nuevas Tecnologías aplicadas a la Arqueología de la producción de las sociedades marítimas púnico-romanas en la Bahía de Cádiz (CEIJ-C03.1)” de la Convocatoria de ayudas a proyectos de investigación “Jóvenes Investigadores CEI·MAR 2019”.

\section{Bibliografía}

BELTRÁN LLORIS, Miguel. 1977: "Problemas de la morfología y del concepto histórico-geográfico que recubre la noción tipo. Aportaciones a la tipología de las ánforas béticas". Methodes classiques et methodes formelles dans l'étude des amphores, pp. 97-131. Ecole Française de Rome. Roma.

BELTRÁN LLORIS, Miguel. 1983: "Las ánforas romanas de salazones de la forma I variante $b$ de la Bética". Homenaje al Prof. Martín Almagro Basch, III, pp. 43-52.

BERNAL-CASASOLA, Darío. 1995: “Tecnología de manufactura de lucernas en época romana: dos elementos de fabricación a molde en la Península Ibérica". En M. VENDRELL-SANZ (ed.): Estudis sobre cerámica antiga. Proceedings of the European Meeting on Ancient Ceramics (Barcelona 1993), pp. 147-150. Generalitat de Catalunya Departament de cultura. Barcelona. BERNAL-CASASOLA, Darío. 2018: "Arqueología de la acuicultura en Hispania. Problemas y reflexiones". En D. BERNAL-CASASOLA y R. JIMÉNEZ-CAMINO (eds.): Las cetariae de Iulia Traducta. Resultados de las excavaciones arqueológicas en la calle San Nicolás de Algeciras (2001-2006), pp. 374-396. Colección Monografías Historia y Arte, Servicio de Publicaciones de la Universidad de Cádiz. Cádiz.

BERNAL-CASASOLA, Darío; ALONSO VILLALOBOS, Carlos; GRACIA PRIETO, Francisco Javier. 2011: "De la acuicultura en Baetica. A propósito de la posible piscina-vivero del yacimiento haliéutico del Cabo Trafalgar (Cádiz)". Zephyrus, LXVII, pp.145-160.

BERNAL-CASASOLA, Darío; VARGAS GIRÓN, José Manuel; MORENO PULIDO, Elena. 2019: "Sítula crateriforme votiva fragmentada de El Olivillo, con dos apliques dionisíacos". En D. BERNAL-CASASOLA, J.M. VARGAS y M. LARA (eds.): 7 metros de la Historia de Cádiz... Arqueología en El Olivillo y en el Colegio Mayor Universitario, pp. 614-620. Servicio de Publicaciones de la Universidad de Cádiz. Cádiz.

BERNAL-CASASOLA, Dario; SÁEZ ESPLIGARES, Antonio; SÁEZ ROMERO, Antonio M.; DÍAZ RODRÍGUEZ, José Juan; LORENZO MARTÍNEZ, Lourdes; TOLEDO CUELLO, Francisco J. 2005: La Carta Arqueológica Municipal de San Fernando (Cádiz). Consejería de Cultura de la Junta de Andalucía. Sevilla.

COLL CONESA, Jaume. 2008: "Hornos romanos en España. Aspectos de morfología y tecnología". En D. BERNAL-CASASOLA y A. RIBERA (eds.): Cerámicas Hispanorromanas. Un Estado de la Cuestión, pp. 113-125. Servicio de Publicaciones de la Universidad de Cádiz. Cádiz.

CORZO SÁNCHEZ, Ramón. 1982: "El ceramista Caius Iunius Dracus". Boletín del Museo de Cádiz, 3, pp. 55-60.

CUOMO DI CAPRIO, Ninina. 1972: "Proposta di classificazione delle fornaci per ceramica e laterici nell'area italiana. Dalla preistoria a tutta l'epoca romana". Sibrium, 11 (1971-72), pp. 371-461.

CUOMO DI CAPRIO, Ninina. 2007: Ceramica in archeologia 2. Antiche tecniche di lavorazione e moderni metodi d'indagine. L'erma di Bretschneider. Roma.

DÍAZ RODRÍGUEZ, José Juan. 2008: “De la arcilla a la cerámica. Aproximación a los ambientes funcionales de los talleres alfareros en Hispania". En D. BERNAL-CASASOLA y A. RIBERA 
(eds.): Cerámicas Hispanorromanas. Un estado de la cuestión, pp. 93-111. Segunda edición. Servicios de Publicaciones de la Universidad de Cádiz. Madrid.

DÍAZ RODRÍGUEZ, José Juan. 2018: “Más allá de la ciudad. Reflexiones de la muerte en el hábitat rural romano de Gades". En M.J. PARODI (coord.): Arqueología del Bajo Guadalquivir V. Arqueología de la muerte, pp. 29-54.

DÍAZ RODRÍGUEZ, José Juan; BERNAL-CASASOLA, Darío. 2017: “De las alfarerías de Baetica. Focos de producción, tecnología y análisis microespacial de las estructuras de producción". En C. FABIAO., J. RAPOSO, A. GUERRA y F. SILVA (coord): Olaria Romana. Seminário Internacional e Ateliê de Arqueologia Experimental, pp. 139-174. UNIARQ. Lisboa.

DÍAZ RODRÍGUEZ, José Juan; SÁEZ ROMERO, Antonio Manuel; MONTERO FERNÁNDEZ, Roberto; MONTERO FERNÁNDEZ, Anabel. 2004: "Alfarería romana en San Fernando (Cádiz). Análisis del proceso productivo cerámico en el hinterland insular de Gades". En D. BERNAL-CASASOLA y L. LAGÓSTENA (eds.): Figlinae Baeticae. Talleres alfareros y producciones cerámicas en la Bética romana (ss. II a.C.-VII d.C.), pp. 649-662. BAR International Series. Oxford.

DÍAZ RODRÍGUEZ, José Juan; SÁEZ ROMERO, Antonio Manuel; SÁEZ ESPLIGARES, Antonio. 2017: "Gallineras - Cerro de los Mártires (San Fernando)”. En R. HIDALGO (ed.): Las Villas romanas de la Bética, vol. II, pp. 94-106. Editorial de la Universidad de Sevilla. Sevilla.

GARCÍA GIMÉNEZ, Rosario; BERNAL-CASASOLA, Darío; VARGAS GIRÓN, José Manuel. 2019: "Arqueometría de la pasta de las sítulas de El Olivillo: productos de la figlina gaditana del Cerro de los Mártires (San Fernando)". En D. BERNAL-CASASOLA, J.M. VARGAS y M. LARA (eds.): 7 metros de la Historia de Cádiz... Arqueología en El Olivillo y en el Colegio Mayor Universitario, pp. 456-460. Servicio de Publicaciones de la Universidad de Cádiz. Cádiz.

GARCÍA VARGAS, Enrique. 1998: La producción de ánforas en la Bahía de Cádiz en época romana. Editorial Gráficas Sol. Écija, Sevilla.
GÓMEZ MUÑOZ, Ma Soledad. 2019a: “La cartografía histórica como fuente para el estudio del paisaje cultural marítimo de la Bahía de Cádiz. Una propuesta analítica y metodológica”. Jangwa Pana, 18 - 2, pp. 256-276.

GÓMEZ MUÑOZ, Ma Soledad. 2019b: "La cartografía histórica y el estudio de los paisajes culturales marítimos. Aplicación metodológica al caso de la bahía de Cádiz". Onoba. Revista de Arqueología y Antigüedad, 7, pp. 171-189.

LAGÓSTENA BARRIOS, Lázaro. 1996: Alfarería romana en la Bahía de Cádiz. Servicio de Publicaciones de la Universidad de Cádiz. Cádiz.

LAGÓSTENA BARRIOS, Lázaro. 2001: La producción de salsas y conservas de pescado en la Hispania Romana (II a.C.-VI d.C.). Colección Instrumenta, Publicaciones de la Uniersidad de Barcelona. Barcelona.

SÁEZ ROMERO, Antonio Manuel; DÍAZ RODRÍGUEZ, José Juan. 2010: “La otra necrópolis de Gadir/Gades. Enterramientos asociados a talleres alfareros en su hinterland insular". En A.M. NIVEAU y V. GÓMEZ (coords.): Las necrópolis de Cádiz. Apuntes de arqueología gaditana en homenaje a J.F. Sibón Olano, pp. 251-337. Diputación de Cádiz y Servicio de Publicaciones de la Universidad de Cádiz. Cádiz.

SÁEZ ROMERO, Antonio Manuel; DÍAZ RODRÍGUEZ, José Juan; SÁEZ ESPLIGARES, Antonio. 2011: "Un aplique antropomorfo masculino barbado de la producción del alfar de Gallineras-Cerro de los Mártires". Boletín Ex Officina Hispana, 3, pp. 6-9.

SÁEZ ROMERO, Antonio Manuel; MONTERO FERNÁNDEZ, Roberto; TOBOSO SUÁREZ, Ernesto; DÍAZ RODRÍGUEZ, José Juan. 2003: "Control arqueológico en el yacimiento púnico-romano de Gallineras (San Fernando, Cádiz)". Anuario Arqueológico de Andalucía. Tomo III, pp. 166-173. 